Imalat Teknolojileri ve Uygulamalar

Cilt: 2, No: 3, 2021 (78-88)

Araştırma Makalesi

e-ISSN: $2717-7475$

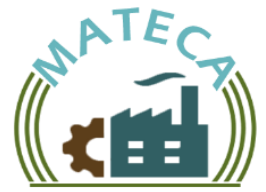

Manufacturing Technologies and Applications

Vol: 2, Issue: 3, 2021 (78-88)

Research Article

e-ISSN: 2717-7475

\title{
Orta ve İleri Düzey Robotik Kodlama Eğitimleri için İnternet Odaklı Sensör Kartı Tasarım ve İmalatı
}

\author{
Samed KAYA ${ }^{1}$ iD, Gürcan SAMTAŞ ${ }^{2 *}$ iD \\ ${ }^{I}$ Düzce Üniversitesi, Fen Bilimleri Enstitüsü, Düzce, Türkiye \\ ${ }^{2}$ Düzce Üniversitesi, Mühendislik Fakültesi, Düzce, Türkiye
}

\section{MAKALE BILGISI}

Alinma: 11.11.2021

Kabul: 26.12.2021

Anahtar Kelimeler:

Nesnelerin interneti

IoT

Robotik kodlama

Sensör modülü

\section{ÖZET}

Son dönemlerde dünyada teknolojide dijital dönüşüm çalışmaları başlatılmıştır. Bu konudaki literatür incelendiğinde nesnelerin interneti konusu eğitim alanında değil, daha çok endüstriyel alanlarda kullanıldığı görülmektedir. Öğrenciler erken yaşlarda elektronik ve yazılım konusunda eğitim alırlarsa, başta geleceğin teknolojisi olan otomasyon olmak üzere savunma sanayi, uzay ve havacılık teknolojileri gibi birçok alanda farklı projeler geliştirebileceklerdir. $\mathrm{Bu}$ çalışmada, dijital dönüşüm çalışmalarından biri olan robotik kodlama eğitimleri, bir diğer üst seviye olan "Nesnelerin İnterneti" konusuyla birleştiren, gerekli olan tüm sensör ve devre elemanları, piyasadaki ihtiyaca göre tespit edilmiş ve literatürden farklı olarak; modüler, kolay ara yüzlü, çocukların motor gelişimine katkı sağlayabilecek bütün sensörleri barındıran bir sensör kartı tasarlanmış ve kasasıyla beraber imalatı yapılmıştır. Bu sayede imal edilen kart ile, otomasyon ve haberleştirme konularının temel olarak öğrenilmesi hedeflenmektedir. Tasarlanan cihaz, çift çekirdekli ve dahili kablosuz bağlantıları bulunan mikroişlemci ile gerekli sensörleri bulunduran elektronik bir sensör kartıdır. Hem kendi üzerinde, hem de internete bağlanabilen herhangi bir cihazla bağlantı kurarak, üzerine yazılmış olan algoritmayı çalıştırabilmektedir. Çalışmada ilk olarak elektronik kart imalatı, daha sonra dış kabuk imalatı ve son olarak test yazılımı yapılarak kart sisteminin üretimi tamamlanmıştır.

\section{Internet-Oriented Sensor Card Design and Manufacture for Intermediate and Advanced Robotics Coding Trainings}

\section{ARTICLE INFO}

Received: 11.11 .2021

Accepted: 26.12 .2021

Keywords:

Internet Of Things

IoT

Robotic coding

Sensor module

\begin{abstract}
Recently, digital transformation studies in technology have been started in the world. When the literature on this subject is examined, it is seen that the subject of the Internet of Things is not used in the field of education, but mostly in industrial fields. If students receive education on electronics and software at an early age, they will be able to develop different projects in many fields such as automation, which is the technology of the future, as well as defense industry, space and aviation technologies. In this study, digital conversion, which is one of the works of robotic coding training, another top-level "Internet of objects" topic, incorporating all that is required for the sensor and circuit components, unlike the literature were identified and according to the needs of the market, modular, easy interface, children with a card that can contribute to the development of the motor sensor is designed and manufacture with all the sensors have been made to the chassis. In this way, it is aimed to learn automation and communication issues mainly with the manufactured card. The designed device is an electronic sensor board that has the necessary sensors with a dual-core microprocessor and built-in wireless connections. It is able to run the algorithm written on it, connecting to any device that can be connected both on its own and on the Internet. In the study, first, electronic card manufacturing, then outer shell manufacturing and finally the production of the card system by making test software was completed.
\end{abstract}




\section{GİRIŞ (INTRODUCTION)}

Nesnelerin İnterneti (IoT); nesnelerin, benzersiz kimlikleri ile kendi aralarında oluşturduğu, dünya çapında bir ağ ve bu ağdaki nesnelerin belirli bir protokol ile birbirleriyle iletişim kurarak bağlantılı olmaları olarak tanımlanır. Ayrıca bu kavramı kabaca; çeşitli haberleşme protokolleri sayesinde birbirleri ile haberleşen ve birbirine bağlanarak, bilgi paylaşarak akıllı bir ağ oluşturmuş cihazlar sistemi olarak da tanımlamak mümkündür [1]. Nesnelerin interneti konusu, pandemi dönemiyle beraber daha çok kullanılmaya başlamıştır. Samarraei ve Özyer yaptıkları çalışmada nesnelerin internetini kullanarak bir akıllı ev projesi gerçekleştirmiştir. Bu proje ile evde bulunan tüm elektronik cihazlar, internet bağlantısı kullanarak telefon uygulaması üzerinden kontrol edilebilir hale getirilmiştir [2]. Ercan ve Kutay yaptıkları çalışmada nesnelerin internetinin endüstri ortamlarında kullanımını araştırmıştır. Ulaştıkları sonuçlarda; nesnelerin interneti ile kontrol edilen makinalarda insan hatasını en aza indirerek gerçek zamanlı bilgi aktarımını sorunsuz şekilde yaptı̆̆ 1 gözlemlenmiştir [3]. Nesnelerin interneti konusunu ülkemizde son zamanlarda daha popüler hale gelmiştir. Günümüzde; üretim, haberleşme, savunma ve diğer tüm alanlarda bu konu, teknolojik olarak gelişim halindedir. Görkem ve Bozuklu bu konuyu ele alarak, nesnelerin internetinin ülkemizdeki mevcut durumu üzerine bir araştırma çalışma yapmışlardır. Yaptıkları çalışma sonucunda nesnelerin interneti konusu ülkemizde daha çok, şehirlerin enerji yönetim sistemlerinin, alışveriş imkanlarının, lojistiğin ve endüstriyel kontrolün akıllı hale gelmesiyle yol aldığını ifade etmişlerdir [4]. Yapılan literatür araştırmalarında, şimdiye kadar yapılan çalışmalarda her iki konuyu da birleştiren bir çalışma bulunmamaktadır. Sadece robotik kodlama eğitimi için yapılmış olan ürünler ve benzer ürünlerin öğrenciler üzerindeki etkilerini araştıran çalışmalar bulunmaktadır [5-7]. Ayrıca bir rekabet ortamında yeni teknolojiler ile öğrencileri tanıştırmayı hedefleyen birçok yarışma yapılmaya başlanmıştır [8, 9]. Dolayısıyla literatürdeki çalışmalara bakıldığında, şimdiye kadar yapılan çalışmalarda robotik kodlama eğitimini ve nesnelerin internetini birleştiren bir çalışma bulunmamaktadır. Bu sonuçlara ve mikroişlemciler hakkında yapılan çalışmalara dayanarak internet bağlantısı destekleyen mikroişlemciler ile bir sensör kartı tasarımı ve imalatı yapılacaktır $[10,11]$. Bu çalışmalardan çıkan sonuçlarda, bu tür cihazların öğrenme ve öğretme konusunda pozitif yönde bir etkisinin olduğu gözlemlenmiştir.

Literatür incelenmiş olup, piyasada kullanılan ürünlerden HaloCode isimli kartın ESP32 işlemcisinin, giriş çıkış pinlerinin ve basit uygulama kitapçığının olması gibi temel benzerlikleri olduğu görüşmüştür [14]. Ancak proje sonucunda imalatı yapılan kartın, çocuklar için daha ilgi çekici ve dayanıklı bir tasarıma sahip olması, çok daha fazla giriş çıkış pininin ve uyumlu sensörünün olması, üzerinde röle, encoder, potansiyometre, motor sürücü entegresi, LCD ekran, butonlar, joystick ve LDR gibi sensörlerin dahili olması sebebiyle harici ekipmana ihtiyaç duymadan kullanılması projeyi öne çıkartmıştır. Bir diğer benzer ürün ise; başta basit bir robotik kodlama kartı olarak tasarlanan ancak küçük bir Wi-Fi işlemcisi eklenip iot kiti haline getirilen Tinylab IOT Kit isimli üründür [15]. Bu üründe işlemci olarak 32 bit $160 \mathrm{Mhz}$ hızıyla çalışan iot eğitim kitine nazaran, 8 bit ve $20 \mathrm{Mhz}$ çalışma hızına sahip işlemci kullanılmıştır. Bu nedenle büyük boyutlu projelerde yetersiz kalmaktadır. Harici takılabilen bir sensör bulundurmayan bu ürün ile yapılabilecek uygulamaların sayısı üzerinde bulunan birkaç adet sensörle sınırlı kalmıştır. Projedeki kart ise Wi-Fi, bluetooth, SPI, UART, I2C protokolleri sayesinde benzer amaçlar için üretilmiş hemen hemen bütün elektronik cihazlarla haberleşmesinin yanı sıra, işlemci pinlerine paralel bağlı soketler kullanılarak piyasada bulunan çoğu sensör kartı da bu çalışmadaki deney seti ile kullanılabilmektedir. Diğer taraftan literatür incelendiğinde nesnelerin interneti konusunu kullanan benzer ürünlerin akademik bir çalışma olarak değil, bir pazarlama ürünü olarak üretildiği ve piyasaya sunulduğu gözlemlenmiştir. Bu çalışmanın en büyük farklarından birisi üzerinde dahili Wi-Fi ve bluetooth bağlantılarının yanı sıra birçok sensörü bulundurması ile birlikte, akademik ve açık kaynaklı bir çalışma olduğu için üzerine sürekli geliştirmeler yapılabilir olmasıdır. Bu farklardan dolayı bu çalışma özgün bir çalışmadır.

$\mathrm{Bu}$ çalışmada, dijital dönüşüm çalışmalarından biri olan robotik kodlama eğitimleri, bir diğer üst seviye olan "Nesnelerin İnterneti" konusuyla birleştiren, gerekli olan tüm sensör ve devre elemanları, piyasadaki ihtiyaca göre tespit edilmiş, bütün sensörler barındıran bir sensör kartı 
tasarlanmış ve imalatı yapılmıştır. Dolayısıyla bu çalışma, yeni nesil eğitimlerin temelini oluşturmaktadır. Bu geliştirilen kart ile uzaktan robotik kodlama eğitimleri yapılabilecektir. Erken yaşta bu tür eğitimleri alıp, temel otomasyon projeleri ile çalışan öğrenciler, sonraki zamanlarda kendine daha da büyük fikirler edinerek ileri teknoloji ürünleri geliştirebileceklerdir.

\section{ELEKTRONİK KART VE DIŞ KABUK TASARIMI (ELECTRONIC BOARD AND SHELL DESIGN)}

\subsection{Elektronik Kart Tasarımı (Electronic Card Design)}

Çalışmada kart tasarımı Autodesk Eagle programında yapılmıştır. Bu programın seçilme nedeni öğrenciler için ücretsiz kullanım lisansı vermesinden dolayıdır. Eagle programında Sparkfun markasının dijital kütüphanelerinde bulunan malzemeler baz alınmıştır. Tasarlanan kart, imalatı kolay olması için 2 katmanlı, 1.6 mm kalınlığında, bakır kalınlığı en az $1 \mathrm{Oz}$ değerinde ve yüzler arası geçişi sağlayan delikler ise en az $0.3 \mathrm{~mm}$ çapında seçilmiştir. Çalışmanın tasarım aşamasında, ilk olarak kullanılacak olan elektronik komponentler için araştırma yapılmıştır. İşlemci seçiminde, dahili kablosuz internet bağlantısı ve bluetooth bağlantısı olması ana kriter olmuştur. Buna dayanarak yapılan araştırmalar sonucunda Espressif marka, ESP32 model mikroişlemci kullanılmıştır (Şekil 1). İşlemci hakkında gerekli teknik veriler incelendikten sonra mikroişlemci ile kullanıma uygun olan ve piyasada en çok kullanılan sensörler için araştırma yapılmıştır. Bunun için öncelikle piyasada bulunan benzer devre kartları incelenmiştir.

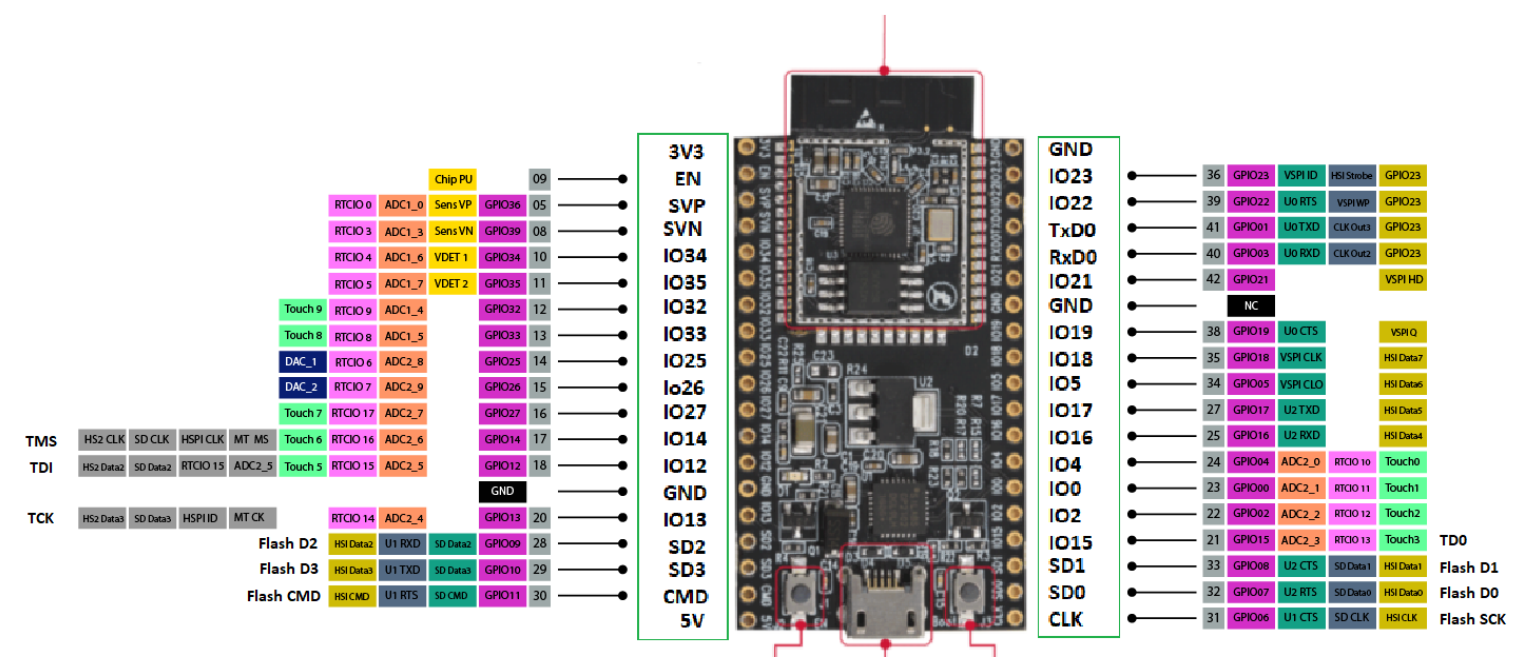

Şekil 1. ESP32 mikroişlemcisinin pin çıkışları (Pinouts of the ESP32 microprocessor) [12]

Tasarlanan kart boyutlarının ortalama bir tablet bilgisayar boyutlarında olmasından dolayı sadece en önemli olan sensörler kullanmaya karar verilmiştir. Robotik kodlamada temel olarak dijital ve analog giriş çıkışlar kullanıldığı için öncelik olarak bu terimleri öğretecek olan buton, iki eksenli ve butonlu joystick, encoder (adım sayıc1), LDR (1şık şiddedi sensörü), buzzer ve 5V röle kullanılmıştır. Ayrıca kullanıcı geri bildirimi vermek için bir adet 20x4 karakterli kristalize LCD ekran kullanılmıştır. Standart koşullarda bu ekranı mikroişlemci ile haberleştirmek için yüksek sayıda iletişim pinine ihtiyaç duyulmaktadır. Ancak tasarlanan kartta boş iletişim pinlerine ihtiyaç olduğundan LCD ekranı kullanmak için I2C protokolü ile iletişim sağlayabilen "PCF8574T" isimli bir ara devre entegresi kullanılmıştır (Şekil 2). Bu sayede boş pin sayısı korunmuştur. 


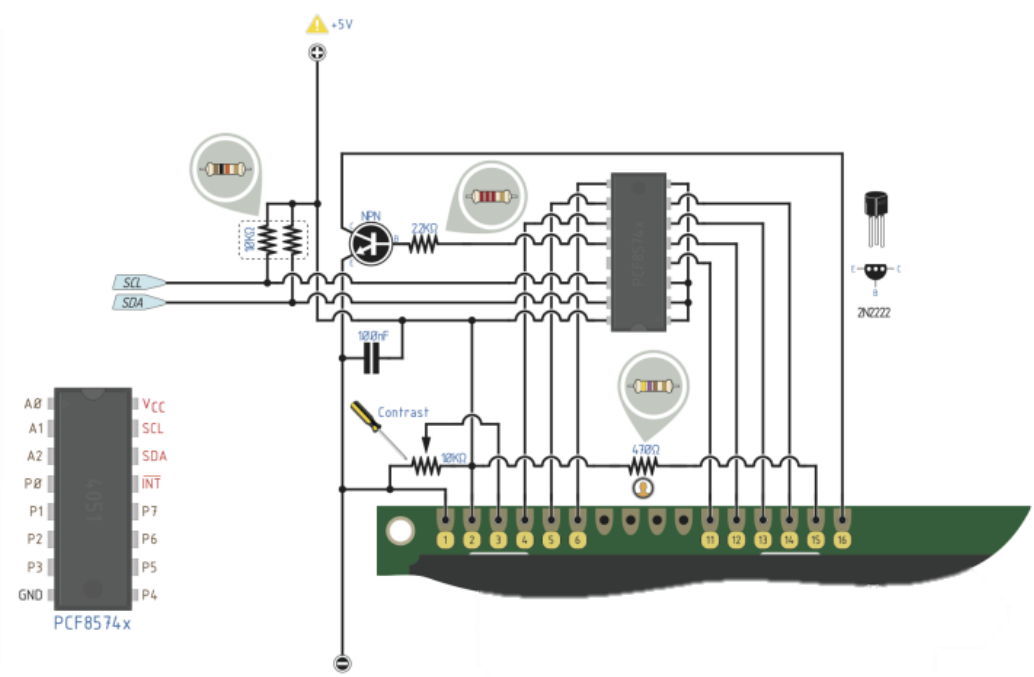

Şekil 2. PCF8574T entegre şematik görüntüsü (PCF8574T integrated schematic view) [13]

Kullanılan sensörlerin sinyal çıkışlarını alabilmek için pinlere paralel olarak RJ45 soketler kullanılmıştır (Şekil 3). Sekiz adet pinden beş tanesi boşta kullanılan sinyal pinleri için ayrılmıştır. Kalan pinler ise topraklama ve güç pinleri olarak ayrılmıştır. Bu sayede farklı kartlarla sorunsuz şekilde haberleşme yapılması sağlanmıştır.

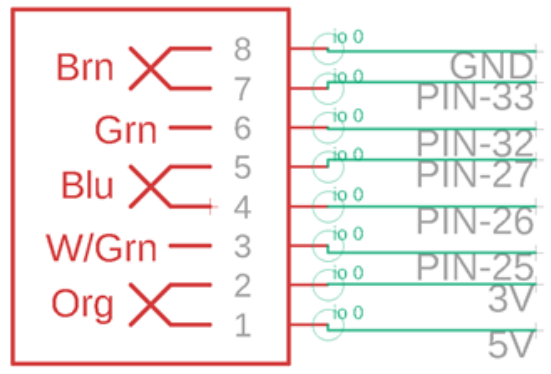

Şekil 3. RJ45 Soket pin çıkışlarının şematik görüntüsü (Schematic view of RJ45 Socket pinouts)

Şekil 3'de, Brn (Kahverengi), Grn (Yeşil), Blu (Mavi), W/Grn (Beyaz/Yeşil) ve Org (Turuncu) renkleri ifade etmektedir. Kartın piyasadaki tüm sensörlerle uyumlu şekilde olması için 'pin header' adında geçen soketker ve jumper kablolar ile bağlantı kurulabilecek şekilde güç ve iletişim portları yapılmıştır. İletişim protokolü olarak ESP32 mikroişlemcisinin desteklediği SPI, I2C ve UART protokolleri bulunmaktadır. Bu portlara kartın ortasında yer verilmiştir.

Kullanılacak sensörleri ve yapılacak olan tasarım üzerine yapılan araştırmalardan sonra şematik oluşturma çalışmalarına başlanmıştır. Şematik oluştururken, güç ve sinyal pinlerinin doğru şekilde bağlanmasına özellikle dikkat edilmiştir. Öncelikle sistemi besleyen voltaj girişi ve devreyi koruyan sigorta, diyot gibi komponentlerin bağlantıları belirlenmiştir. Ardından mikroişlemcinin şematik görüntüsü eklenerek sinyal çıkışları ve işlemci güç pinlerinin bağlantıları yapılmıştır. Sistemin bu şekilde sorunsuz çalışabileceğine karar verildikten sonra daha önceden belirlenen sensörlerin gerekli kütüphane dosyaları çalışmaya eklenerek bağlantıları yapılmıştır (Şekil 4). 


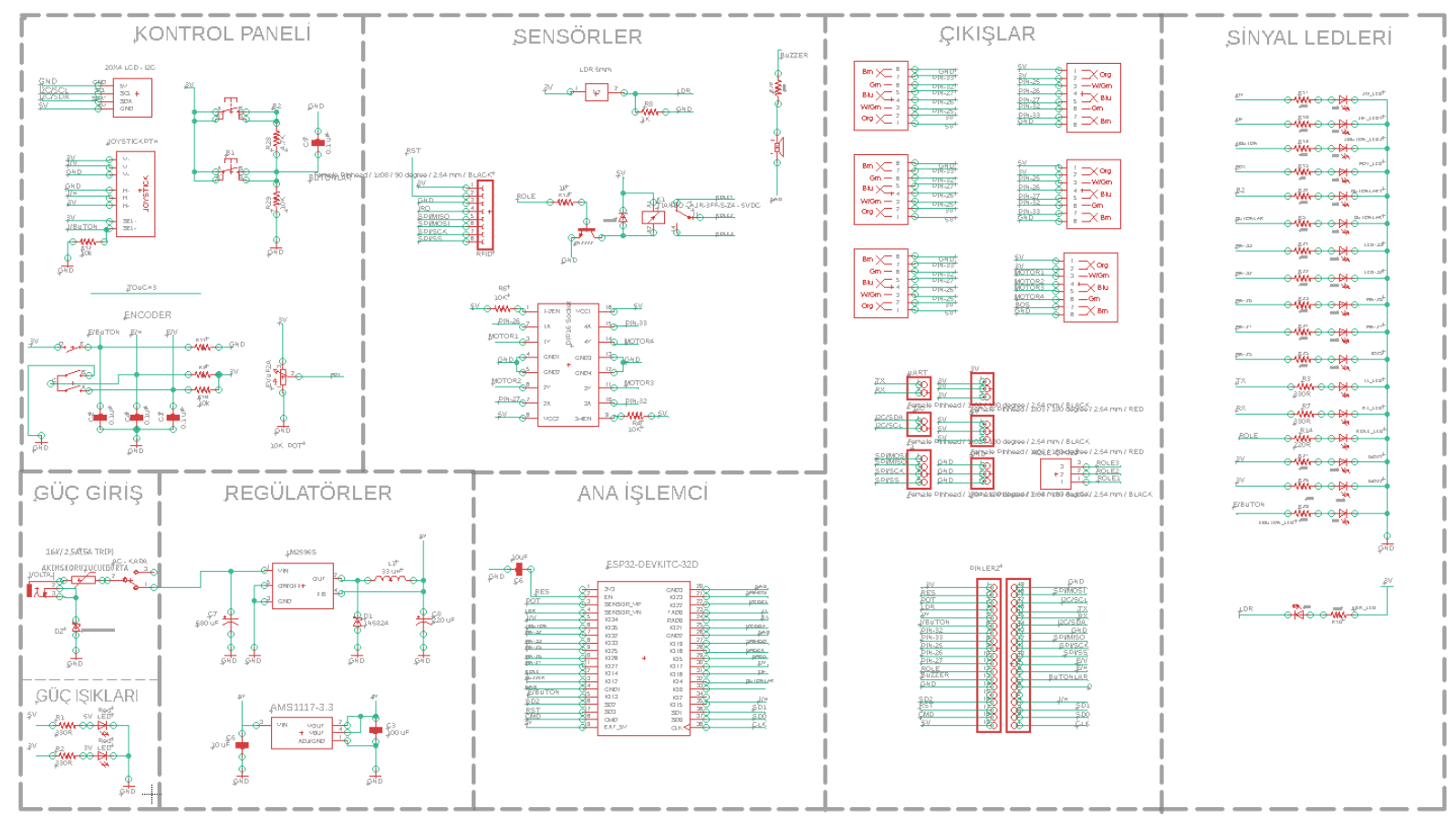

Şekil 4. Tüm devrenin şematik bağlantısı (Schematic connection of the whole circuit)

Şematik çalışma planı tamamlandıktan sonra sıra elektronik komponentlerin kartta konumlandırılmasına ve bakır yollarının çizilmesine gelmiştir. Öncelikle kabataslak olarak tüm komponentler bir çizim içerisinde toplanmıştır. Bu sayede kartı tasarlamak için gerekli olan dış boyutlar 175x125 mm boyutlarında olmuştur (Şekil 5). Üretim maliyetini ve zamanını düşürmek için standart imalat kurallarına göre bir tasarıma başlanmıştır. Bunun için kullanılacak olan direnç, diyot, transistör, regülatör gibi elemanların imalatını kolaylaştırmak için tek taraflı montaj edilebilen YME (yüzey montaj devre elemanları) kılıfında seçilmiştir.

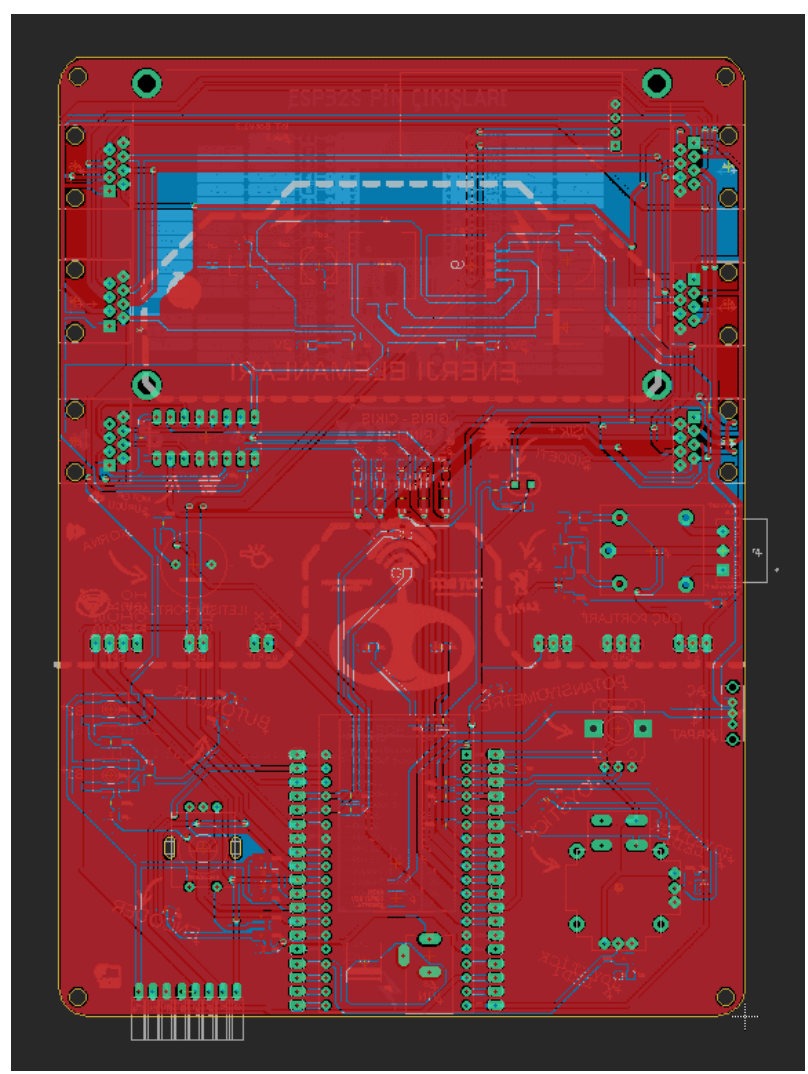

Şekil 5. Kartın dış ölçülerinin ve üst bakır katmanının görüntüsü (Image of card outer dimensions and top copper layer) 
Sistemde en çok kullanılan bağlantını topraklama hattı olduğundan üst bakırın tamamen topraklama hattı olarak kullanılmasına karar verilmiştir. Ayrıca bu sayede kartta oluşabilecek kısa devreler için ek bir koruma yolu sağlanmıştır. Tüm elemanlar standart üretim kurallarına göre yerleştirildikten sonra kartın tasarım aşaması tamamlanmıştır. Ardından kartın üç boyutlu görüntüsü alınmıştır. Bu sayede imal edilen kartın dış kabuğu tasarlanmıştır.

Kart üzerinde boş bırakılan 5 adet sinyal pinine bağlı olan soketler ile, sıcaklık, nem, basınç gibi piyasada bulunan birçok sensörler kullanılabilmektedir. Ayrıca aynı hatlar üzerinde bulunan enerji ve topraklama hatları sayesinde harici bir güç kaynağına gerek kalmamaktadır.

\subsection{Sensör Kartı Dış Kabuk Tasarımı (Sensor Board Outer Shell Design)}

Üç boyutlu modeli alınan elektronik kart, bilgisayar destekli tasarım programı içerisinde tekrardan montaj çalışması olarak oluşturulmuştur. Ardından üç boyutlu model üzerinden katı model oluşturulmaya başlanmıştır (Şekil 6).

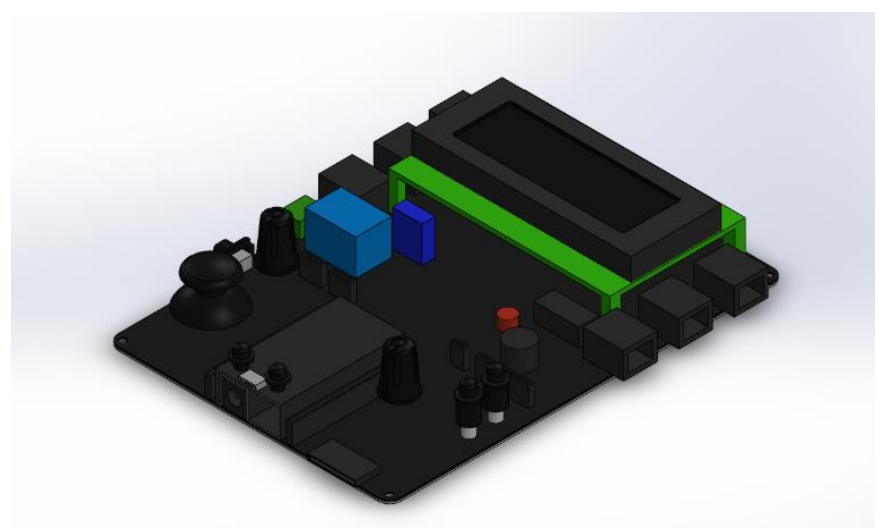

Şekil 6. Komponenler eklenmiş kartın üç boyutlu görüntüsü (Three-dimensional view of the card with components added)

Tasarıma başlamadan önce montaj üzerinden gidilerek kabaca bir dış kabuk tasarımı yapılmıştır. Tasarımı oluştururken dışarıdan müdahale yapılacak olan sensörlerin kontrolüne engel olmayacak şekilde bir tasarım planlanmıştır. Encoder, joystick, butonlar ve giriş çıkış portlarının boşluklu olması sağlanmıştır. Model bir üst kapak, bir alt kapak ve iki adet dış görseli güçlendiren çıtadan oluşturulmuştur. Ayrıca içeride kalan sensörlerin kabuk dışından da kontrol edilebilmesi için küçük parçalar tasarlanmıştır. $\mathrm{Bu}$ sayede dış kabuk tüm kartla uyumlu hale getirilmiştir (Şekil 7). Tasarımda dikkat edilen bir diğer kural ise; tasarımın üç boyutlu yazıcıdan üretime uygun olmasıdır. Bundan dolayı kartın kalınlığı en az 1.5 mm olmuştur. Üç boyutlu yazıcılarda iç doluluğu istenilen şekilde ayarlanabildiğinden ürüne ağırlık katmadan hacmini arttırabilir şekilde üretim planlanmıştır. 


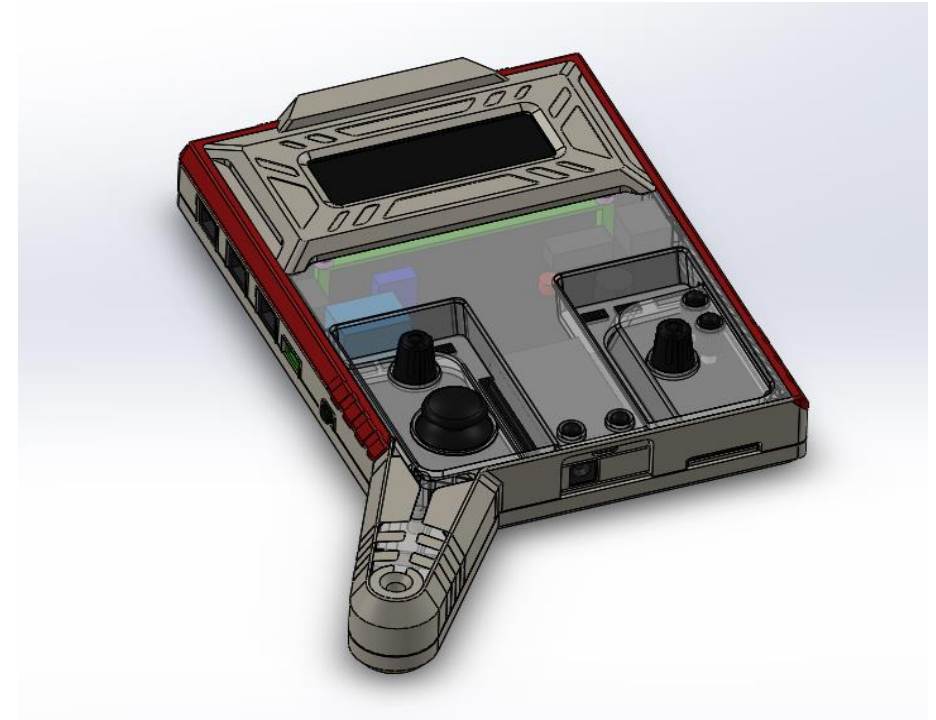

Şekil 7. Tasarlanan diş kabuğun görüntüsü (Image of the designed outer shell)

\section{SENSÖR KARTI İMALATI (SENSOR BOARD MANUFACTURING)}

\subsection{Elektronik Kartın İmalatı (Electronic Card Manufacturing)}

Tasarımı biten kartın ilk olarak elektronik komponent temini yapılmıştır. Ardından bakır kaplı plakaya işlenmiş elektronik kart imalatı (PCB) yapılmıştır. Bu aşamada iki yüzlü plaka üzerine bilgisayarda tasarlanmış olan yollar ve katmanlar arası geçişi sağlayan delikler (via) işlenmiştir. Ardından yalıtkanlığı sağlaması için bakır katmanın üzerine bir boya katmanı ve gerekli bilgilendirmeler için yazı katmanı eklenmiştir. Bu işlemler ardından boş elektronik kartının imalatı tamamlanmıştır.

Hazırlanan boş kartlar üzerine elektronik komponenlerin montajını yapmak için dizgi işlemi gerçekleştirilmiştir (Şekil 8). Tasarım dosyasından alınan komponenlerin konum ve açı bilgilerinin bulunduğu bir liste ile dizgi makinasına yükleme yapılarak dört işlemde dizgi işlemi tamamlanmıştır. İlk olarak, komponentlerin lehimleneceği altın kaplı noktalara makine yardımıyla sıvı lehim yerleştirilmiştir. Tüm altın kaplı yerler sıvı lehim ile kaplandıktan sonra ikinci aşama olan komponentleri yerlerine yerleştirme işlemi yapılmıştır. Tasarım dosyasından alınan bilgilere göre yerleştirilen komponentler, üçüncü aşama olarak ısıtılmış fırının içerisinde ilerleyen hareketli bir konveyörde lehimi eritip komponenlerin montajlanması sağlanmıştır. Bu sayede tek yüzeyden montajlanan komponenlerin montaj işlemi tamamlanmıştır. Son aşama olarak delik içinden montajlanan komponentler el havyası ile montajlanarak elektronik kartın dizgi işlemi tamamlanmıştır (Şekil 8). 


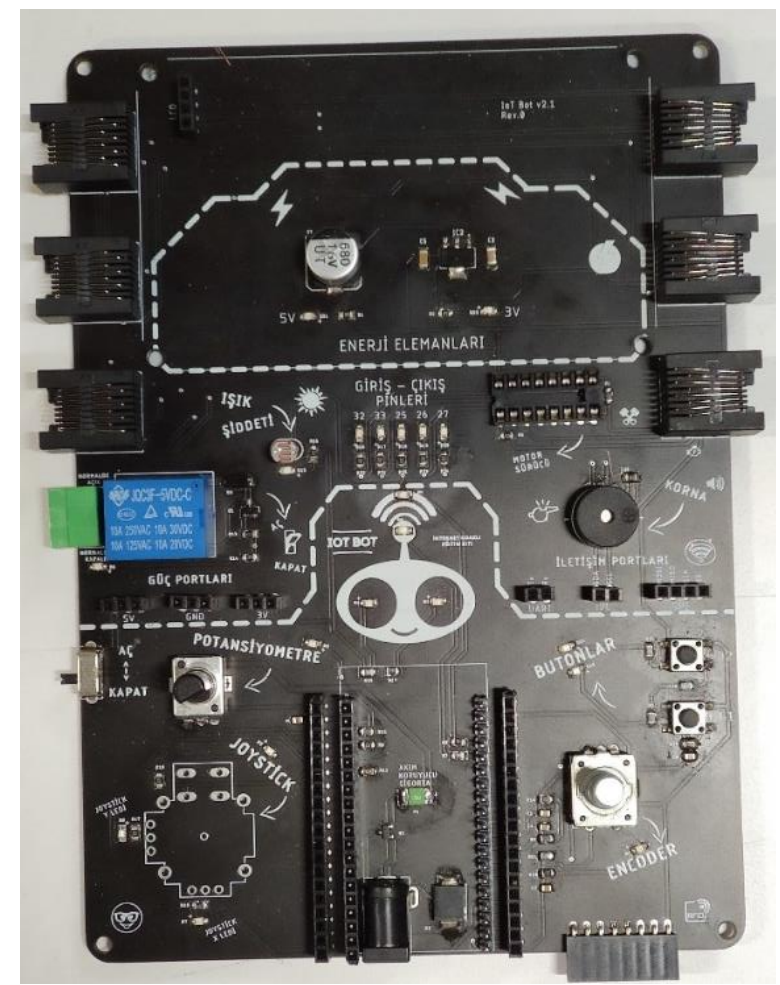

Şekil 8. Dizgi işlemi tamamlanmış kart (Completed card)

İmalatı tamamlanan kartın test edilmeden önce üzerinde kalan lehim pastası kalıntılarından arındırılması için özel temizleme sıvıları içerisinde temizliği yapılmıştır. Temizliği biten kartın uygun bir ortamda güç girişlerinden enerji verilerek elektronik bağlantılar test edilmiştir. Bu aşamada mikroişlemci içerisinde çalıştırılacak olan herhangi bir yazılım olmadığı için sadece enerji hatlarının kontrolü yapılmıştır. Güç verildiğinde herhangi bir sorun olmadığı gözlemlendikten sonra bir sonraki aşama olan dış kabuk imalatına geçilmiştir.

\subsection{Sensör Kartı Dış Kabuk İmalatı (Manufacturing of Sensor Board Outer Shell)}

Elektronik kart imalatı tamamlandıktan sonra kartı koruyucu dış kabuk imalatına başlanmıştır. Daha önceden bilgisayar ortamında tasarlanmış olan dosyaların üç boyutlu yazıcıdan işlenebilmesi için STL (Stereolithography) formatında çıktı alınmıştır. Alınan dosyalar bir dilimleyici programına eklenerek model ayarları yapılmıştır. Tasarlanan modeller üç boyutlu yazıcının baskı alanının büyük olduğundan dolayı ikiye bölünerek basılmıştır. Baskı ayarları yapılırken iç doluluk oranı \%50 seçilerek parçanın kütlesinin çok fazla olmaması sağlanmıştır. Ayrıca katman kalınlığı olarak pürüzsüz bir yüzey istendiğinden dolayı $0.2 \mathrm{~mm}$ yükseklik seçilmiştir. Bu ayarlar yapıldıktan sonra dilimleyici program üzerinden üç boyutlu yazıcıya yollamak için bilgisayar destekli üretim dosyaları elde edilmiştir. Dört seferlik ve toplamda 120 saatlik bir baskı ardından ürünler sorunsuz şekilde elde edilmiştir (Şekil 9). 


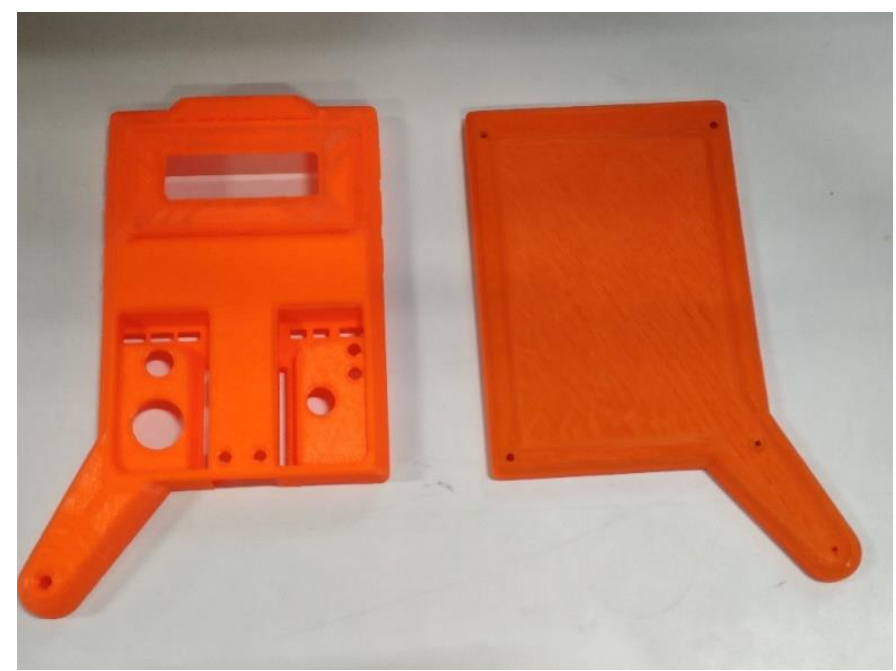

Şekil 9. Üç boyutlu yazıcıdan elde edilmiş dış kabuk görüntüsü (Outer shell image obtained from a 3D printer)

\section{TEST YAZILIMI OLUŞTURMA (CREATING TEST SOFTWARE)}

Dış kabuk imalatı tamamlandıktan sonra sensör kartının dışına montajlanmıştır. Bu sayede son tasarıma ulaşılmıştır. Enerji testlerini geçen kartın sensörlerden gelen verileri doğru bir şekilde iletip iletmediğini görmek için, kart üzerinde bulunan tüm sensörleri bulunduran bir algoritma çıkarılmıştır. Bu algoritma sırasıyla tüm sensörlerin kütüphane dosyaları ve çalışma aşamalarını içermektedir. Ardından çıkarılan bu algoritma karta yüklemek için Arduino IDE derleyicisi üzerinden $\mathrm{C}++$ dilinde yazılarak kontrol edilmiştir. Derleme işlemi tamamlandıktan sonra kart ile USB üzerinden bağlantı kurularak test yazılımının karta yüklenmesi sağlanmıştır. Test yazılımı yüklenen kart sirasıyla tüm sensörleri test ederek gerekli bilgilendirmeleri üzerinde bulunan ekrandan kullanıcıya bildirmiştir. Tüm sensörlerin sorunsuz şekilde çalıştığını gördükten sonra kart son haline ulaşmıştır (Şekil 10).

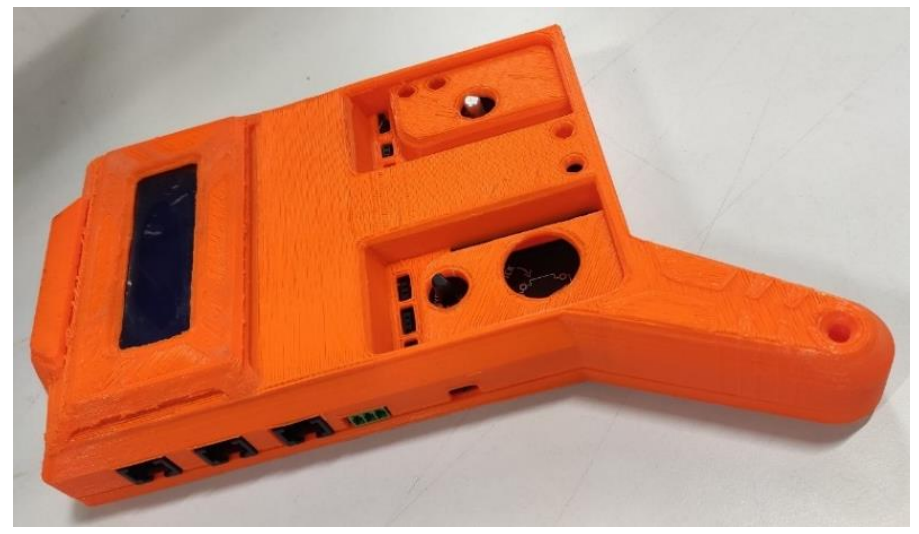

Şekil 10. Sensör kartının son görüntüsü (Final image of the sensor board)

\section{SONUÇLAR (CONCLUSIONS)}

$\mathrm{Bu}$ çalışmada, dijital dönüşüm çalışmalarından biri olan robotik kodlama eğitimleri, bir diğer üst seviye olan "Nesnelerin İnterneti” konusuyla birleştirilmiştir. Bu sayede otomasyon ve haberleştirme konularını temel olarak öğrenilmesine yardımcı olacak bir kart tasarımı ve imalatı yapılmıştır. Bu çalışmadan elde edilecek sonuçları şu şekilde sıralamak mümkündür;

- Çalışmada kart tasarımı Autodesk Eagle programında yapılmıştır.

- Tasarlanan kart, imalatı kolay olması için 2 katmanlı, 1.6 mm kalınlığında, bakır kalınlığı en az $1 \mathrm{Oz}$ değerinde ve bakır yüzler arası geçişi sağlayan delikler ise en az $0.3 \mathrm{~mm}$ çapında seçilmiştir. 
- Çalışmada Espressif marka, ESP32 model mikroişlemci kullanılmıştır.

- Seçilen işlemcinin üzerinde bulunan dahili Wi-Fi ve bluetooth bağlantıları sayesinde iot uygulama örnekleri yapılabilmektedir.

- Çalışmada, piyasada bulunan kartlar incelenerek eksik noktalarının belirlenerek, yeni bir eğitim kiti tasarımı yapılmıştır.

- Çalışmada, Robotik kodlamada temel olarak dijital ve analog giriş çıkışlar kullanıldığı için bu duruma dikkat ederek bu terimleri öğretecek olan buton, iki eksenli ve butonlu joystick, encoder (adım sayıcı), potansiyometre, motor sürücü, led, LDR (1şık şiddedi sensörü), buzzer ve 5V röle kullanılmıştır. Ayrıca kullanıcı geri bildirimi vermek için bir adet 20x4 karakterli kristalize LCD ekran kullanılmıştır.

- Çalışmada tasarlanan kartta boş iletişim pinlerine ihtiyaç olduğundan LCD ekranı kullanmak için I2C protokolü ile iletişim sağlayabilen "PCF8574T" isimli bir ara devre entegresi kullanılmıştır. Daha sonra bağlanan bu ekran işlemci içerisine yazılan yazılım ile kullanılmiştır.

- Kartta kullanılan sensörlerin sinyal çıkışlarını alabilmek için pinlere paralel olarak bağlanan RJ45 soketler kullanılmıştır.

- İmalatı yapılan ana kartın dış boyutları 175x125 mm ebatlarındadır

- Dış kabuk; bir üst kapak, bir alt kapak ve iki adet dış görseli güçlendiren çıtadan oluşturulmuştur. Ayrıca içeride kalan sensörlerin kabuk dışından da kontrol edilebilmesi için küçük parçalar tasarlanmıştır.

- Çalışmada kullanılan sensör kartı özgün olarak tasarlanmış ve imalatı (PCB) yapılmıştır

- Sensör kartı dış kabuk imalatı için üç boyutlu yazıcı kullanılmış, baskı ayarları yapılırken iç doluluk oranı \%50 seçilmiştir. Ayrıca katman kalınlığı olarak pürüzsüz bir yüzey istendiğinden dolayı $0.2 \mathrm{~mm}$ yükseklik seçilmiştir.

- Kart içerisine yazılacak olan programlar için Arduino IDE derleyicisi üzerinden $\mathrm{C}++$ dili kullanılmıştır.

- Kart için yazılan test yazılım github sayfasına" IOTBOT-Firmware" isminde yüklenerek herkesin ulaşabileceği hale getirilmiştir [16].

Geliştirilen bu deney seti Arduino kartların geliştirilişmiş halidir. Kart üzerindeki sensörler kullanılarak standart kitlerde yapılan; led ışık yakma, röle açma kapatma, sıcaklık ölçme ve benzeri basit uygulamaları internetle birleştirip akıllı cihazlar ve uygulamalar yapılabilmektedir. Örneğin üzerindeki röleye bağlanan bir 1şık, kahve makinası ya da 1sıtıcı kombi internet aracılığıyla başka bir karttan ya da mobil uygulamadan veri alarak kontrol edilebilir. Her türlü Arduino uyumlu sensörlerden okunan veriler açık sunuculara iletip çift yönlü iletişim kurulabilir. Bağlantı noktası olarak yayın yapabilmesi özelliği sayesinde internet bağlantısı olmayan yerlerde dahi eğitici bir kit olarak kullanılabilmektedir. Sonraki yapılacak çalışmalarda tasarlanan bu kartın günümüz eğitimlerine ayak uyduracak şekilde uzaktan eğitimde kullanılabilmesi için geliştirmeler yapilacaktır.

\section{TEŞEKKÜR (ACKNOWLEDGMENT)}

$\mathrm{Bu}$ çalışma Düzce Üniversitesi Bilimsel Araştırma Projeleri kapsamında desteklenmiştir. Yazarlar, Düzce Üniversitesi Bilimsel Araştırma Projeleri Koordinatörlüğüne desteklerinden dolayı teşekkür eder (Proje no: 2021.06.06.1206).

\section{KAYNAKLAR (REFERENCES)}

1. Karel yüz yüze teknoloji, Nesnelerin interneti nedir, https://www.karel.com.tr/blog/internet-thingsnesnelerin-interneti-nedir-cihazlarin-etkilesim-trendleri, 10.11.2021.

2. Y.S.H. Al-Samarrae1, Smart home design with IoT (Home automation), Yüksek Lisans Tezi, Çankaya Üniversitesi Fen Bilimleri Enstitüsü Ankara, Türkiye, 2018.

3. E. Tuncay, K. Mahir, Endüstride nesnelerin interneti (IoT) uygulamaları, Afyon Kocatepe Üniversitesi Fen ve Mühendislik Bilimleri Dergisi, 16(3): 599-607, 2016. 
4. G. Levent, B. Mehmet, Nesnelerin interneti: Yapılan çalışmalar ve ülkemizdeki mevcut durum, Gaziosmanpaşa Bilimsel Araştırma Dergisi, 13: 47-68, 2016.

5. G. Süleyman, Y. İkbal, Bilişim teknolojileri öğretmenleri ve öğrencilerinin robotik ve kodlama dersine ilişkin görüşleri, Düzce üniversitesi sosyal bilimler enstitüsü dergisi, 8(1): 178-196, 2018.

6. B.A. Kök, Beşinci sınıf öğrencilerinin grup çalışması ile robotik kodlama deneyimlerinin incelenmesi, Yüksek Lisans Tezi, Afyon Kocatepe Üniversitesi Fen Bilimleri Enstitüsü, Afyonkarahisar, Türkiye, 2019.

7. F.N. Aksu, Bilişim teknolojileri öğretmenleri gözünden robotik kodlama ve robotik yarışmaları, Yüksek Lisans Tezi, Balıkesir Üniversitesi Fen Bilimleri Enstitüsü, Balıkesir, Türkiye, 2019.

8. F. Başçiftçi, K.A. Gündüz, nesnelerin interneti uyumlu mikrodenetleyiciler üzerine bir araştırma., Selçuk Üniversitesi Sosyal ve Teknik Araştırmalar Dergisi, 18: 62-71, 2019.

9. H. Altınpulluk, Nesnelerin interneti teknolojisinin eğitim ortamlarında kullanımı, Açık öğretim Uygulamaları ve Araştırmaları Dergisi, 4(1): 94-111, 2018.

10. E. Öztemel, Eğitimde yeni yönelimlerin değerlendirilmesi ve eğitim 4.0, Üniversite Araştırmaları Dergisi, 1(1): 25-30, 2018.

11. M. Topaloğlu, E. Tekkanat, G. Malakçı, Akıllı Cihaz ve İnsan Etkileşimi: Nesnelerin İnterneti, Ege Eğitim Teknolojileri Dergisi, 3(1): 11-19, 2019.

12. James Wilson, Esp32 Pinout, Datasheet, Features \& Applications, https://www.theengineeringprojects.com/2020/12/esp32-pinout-datasheet-features-applications.html, 16.09.2021.

13. Alberto Piganti, Conectar Una Pantalla LCD Hitachi 44780 Vía I2C, http://diwo.bq.com/conectaruna-pantalla-lcd-hitachi-44780-via-12c/, 02.10.2021.

14. Makeblock-HaloCode, https://www.makeblock.com/steam-kits/halocode ve https://www.robotistan.com/halocode-iot-tabanli-kodlama-platformu, 23.12.2021.

15. TinyLab IoT Kit, https://www.tinylab.cc/ ve_https://www.elektrovadi.com/urun/tinylab-iot-kittinylab-kitabi-hediyeli, 23.12.2021.

16. GITHUB, https://github.com/samed5497/IOTBOT-Firmware, 23.12.2021 